\title{
Acinetobacter haemolyticus
}

National Cancer Institute

\section{Source}

National Cancer Institute. Acinetobacter haemolyticus. NCI Thesaurus. Code C86092.

A species of aerobic, Gram negative, rod and cocci shaped bacteria assigned to the phylum Proteobacteria. This bacteria is nonmotile, oxidase negative, catalase positive, gelatinase negative and can carry out glucose, galactose, mannose and xylose oxidation. A. haemolyticus is rarely pathogenic in humans. 